


\section{Iconografia musical na obra de Henri Rousseau}

\section{Musical iconography in Henri Rousseau's work}

palavras-chave: pintura; música; analogias; Henri Rousseau.

keywords: Painting; Music; Analogies; Henri Rousseau.

*Universidade de São Paulo (USP), Brasil.

DOI: 10.11606/issn.2178-0447. ars.2019.154437
Número significativo de artistas, teóricos da música e historiadores da arte exploraram a diversidade e complexidade dos nexos entre pintura e música ao longo dos séculos. No domínio das artes visuais, as referências à música são abundantes, ganhando expressão tanto pelos temas iconográficos quanto pela reflexão sobre os fundamentos da linguagem musical (ritmo, harmonia, cromatismo). A partir das analogias e interferências entre as duas formas de expressão, propomos uma leitura crítica desse fenômeno na obra de Henri Rousseau, artista francês que desenvolveu uma iconografia particular inspirada no assunto, através da qual explora as possibilidades de representação pictórica da música, tendo em vista efeitos de sentido integrados às suas narrativas visuais.

A significant number of artists, music theorists and art historians have explored the diversity and complexity of the nexus between painting and music over the centuries. In the field of visual arts, references to music are abundant, gaining expression both through iconographic themes and reflections on the fundamentals of musical language (rhythm, harmony, chromaticism). From the analogies and interferences between these two forms of expression, we propose a critical reading of the phenomenon in the work of Henri Rousseau, French artist who developed a particular iconography inspired by the theme, through which he explores the possibilities of the pictorial representation of music and intends to create effects of meaning which are integrated into his visual narratives. 
Numero significativo de artistas, estudiosos de la música y historiadores de arte han investigado la diversidad y complejidad de los nexos entre la pintura y la música. En las artes visuales, las referencias a la música son abundantes y ganan expresión tanto por los temas iconográficos cuanto por la reflexión acerca de los fundamentos del lenguaje musical (ritmo, armonía, cromatismo). A partir de las analogias y intereferencias entre las dos formas de expresión, proponemos una lectura critica del fenómeno en la obra de Henri Rousseau, artista francés que ha creado una iconografia particular inspirada en el tema, por medio de la cual investiga las especificidades de la representación pictórica de la música, produciendo sentidos integrados a sus narrativas visuales.

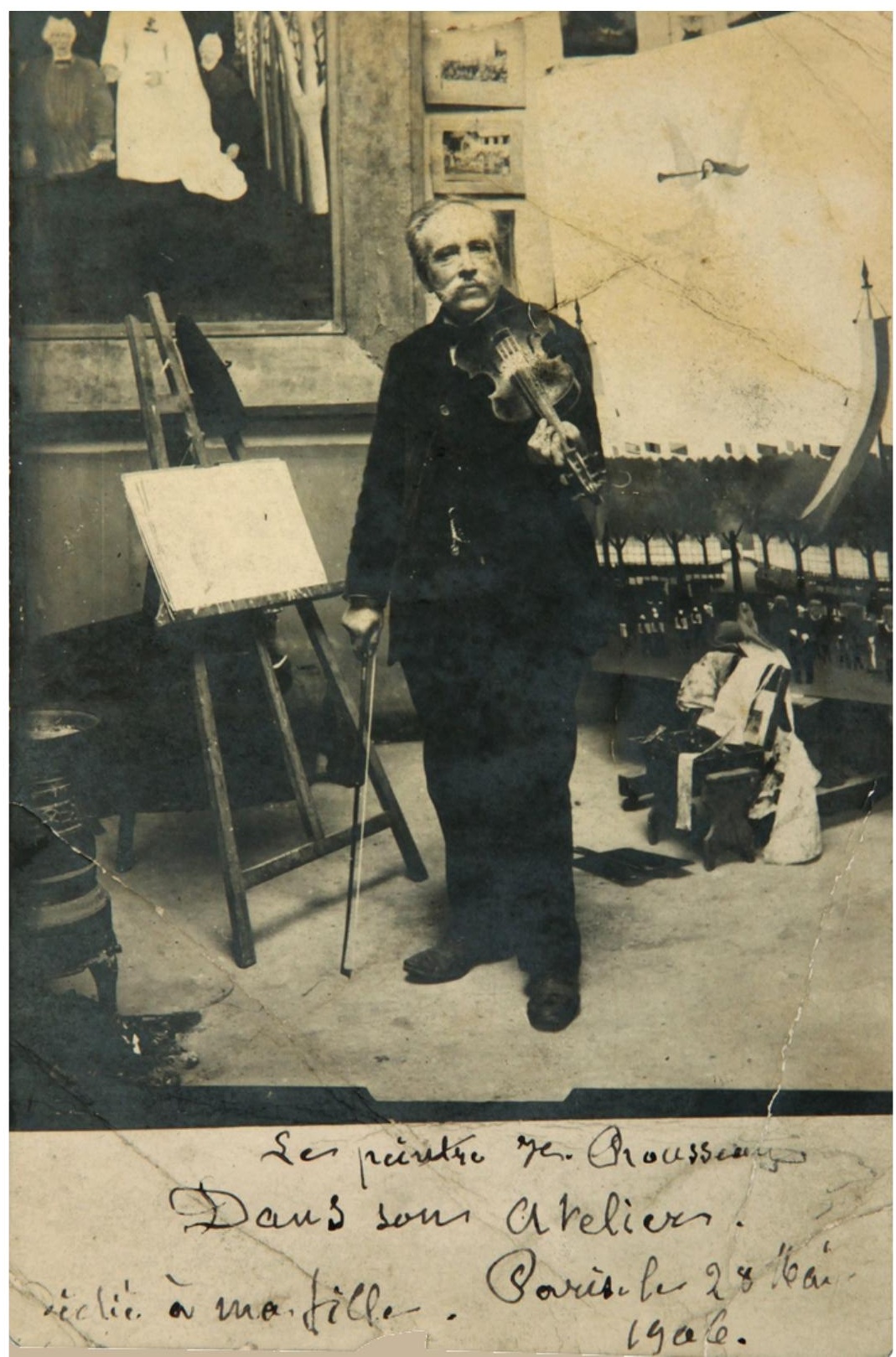

164

Andrei Fernando F. Lima

Iconografia musical na obra de

Henri Rousseau

palabras clave:

pintura; música; analogía; Henri Rousseau.

Figura 1:

Anônimo, Henri Rousseau em seu ateliê, 1906. Fotografia. Coleção particular. 
Pintura e música, duas linguagens distintas e, ao mesmo tempo, próximas, formal e conceitualmente falando. Noções como "cromatismo" e "ritmo", por exemplo, tão características de uma e outra arte, são de modo frequente intercambiáveis. Fala-se, assim, da qualidade cromática de certas composições e também no ritmo das formas de uma imagem. A estrutura de uma obra musical ou pictórica pode igualmente relacionar elementos comuns, tais como o ponto, a linha e o plano, que respondem por inflexões e movimentos no tempo ou no espaço. Por isso mesmo, são inúmeras as possíveis e plausíveis associações entre pintura e música, entre sons e cores, entre cadências e formas gráficas. Assim, a efetiva correlação entre as duas linguagens permeia a história da arte, compreendendo expressões que abrangem desde a combinação entre música e imagem realizada pelos povos aborígenes em seus rituais até o ambicioso projeto romântico de Philipp Otto Runge, que envolvia a criação de grandes composições plásticas destinadas a serem apreciadas com poesia e música em um ambiente arquitetônico.

Há, ainda, a ideia de musicalidade na pintura, quando a distribuição de determinados elementos anuncia o valor dos sons (a posição de um ponto em relação a uma linha) ou quando a seleção das cores indica o caráter grave ou agudo de um som. Na pintura moderna, quem mais admirou essa proximidade e refletiu sobre suas consequências foi sem dúvida o russo Wassily Kandinsky, que procurava não apenas sugerir ritmos e melodias através de suas composições visuais, mas associar, inclusive, cores à tonalidade musical dos instrumentos. Além disso, a musicalidade reflete-se na obra de um sem-número de artistas antigos e modernos quando se trata da própria representação, isto é, da orquestração de cenas nas quais a música desempenha papel relevante. Nesse caso, a transmissão de um ritmo ou de uma melodia pode se dar pela presença substancial de elementos sonoros (instrumentos ou grupos musicais) ou pela simples sugestão de uma música ambiente, como no quadro de Pierre-Auguste Renoir Baile no Moulin de la Galette (1876).

Uma situação interessante à análise seria, então, o caso de um artista que reunisse, a um só tempo, competências pictóricas e musicais refletidas em sua obra, alguém que se poderia chamar de "pintor-músico". O artista autodidata Henri Rousseau é um 
dos exemplos que se prestam a esse estudo, já que dominava tanto a arte da pintura, pela qual é hoje lembrado, quanto a arte da música, que praticou paralelamente ao longo da vida. Conhecido como o Aduaneiro (le Douanier), por seu emprego na Aduana de Paris, Rousseau é um dos casos singulares da história da arte tido como iniciador da pintura naïf, ou ingênua, ao criar uma obra particularmente original e distante das convenções estéticas. Seu trabalho, já bastante debatido, permanece fértil para as mais diversas interpretações e aproximações, como bem ilustra a relação entre suas pinturas e seus escritos - pois ele também cultivou a poesia e a dramaturgia. ${ }^{1}$ Isso posto, a investigação das implicações da música em sua produção visual, se não inédita, ainda exige aprofundamento crítico, e é nesse estro de espírito que se apresenta a atual reflexão.

Os dons artísticos de Rousseau manifestaram-se desde cedo, embora "a perda de fortuna de seus pais" o tenha obrigado "a seguir de início uma outra carreira" ${ }^{2}$. Foi assim, por exemplo, que, aos dezesseis anos, por ocasião da conclusão de seus estudos, recebeu dois prêmios que já anunciavam sua vocação: um de desenho e outro de música vocal. Mais tarde, nas fileiras do $51^{\circ}$ regimento de infantaria, durante sua passagem pelo exército, chegou a se destacar como flautista. $\mathrm{O}$ poeta Guillaume Apollinaire, um dos amigos mais próximos do Aduaneiro no meio intelectual, ao escrever um artigo sobre ele, em 1914, registrou que Rémy de Gourmont lembravase de ter visto o pintor, ainda em um momento em que este vivia na obscuridade, "em certos cruzamentos da Rive Gauche onde o velho Rousseau tocava, ao violino, melodias de sua composição e fazia as pequenas operárias cantarem o som em voga”3. E, no mesmo texto, o autor afirma que "ele tocava também, naqueles tempos, nos concertos das Tulherias"

De tudo isso, porém, destaca-se o autodidatismo do artista, que se dedicava à música nas horas livres, ainda que, muitas vezes, com a finalidade de complementar seus rendimentos, ministrando aulas particulares para os jovens do bairro em que vivia. Uma placa em seu ateliê, segundo Wilhelm Uhde, trazia a inscrição: "Curso de dicção, música, solfejo" ${ }^{5}$. Daí a feliz lembrança de Apollinaire, que evoca em seu artigo a expressão francesa "violon d'Ingres" ao falar da prática musical do Aduaneiro, expressão esta que descreve justamente uma atividade artística desenvolvida fora de uma profissão, em outras
166

Andrei Fernando F. Lima

Iconografia musical na obra de Henri Rousseau

1. Rousseau redigiu certo número de "legendas" em verso e prosa para explicar o conteúdo de alguns de seus quadros e escreveu três peças de teatro: Une Visite à l'Exposition de 1889 (vaudeville em 3 atos e 10 quadros), $L a$ Vengeance d'une orpheline russe (drama em 5 atos e 19 quadros) e L'Étudiant en goguette (comédia em 2 atos e 3 quadros). Os dois primeiros títulos foram publicados em 1947, e a edição completa das peças apareceu apenas em 2010.

2. Conforme afirma o artista em uma nota biográfica redigida em 1895. 0 fac-símile do documento encontra-se reproduzido em: PAYRÓ, Julio E. El Aduanero Rousseau. Biblioteca Argentina de Arte. Buenos Aires: Editorial Poseidon, 1944, p. 25. Transcrição e tradução de minha autoria.

3. APOLLINAIRE, Guillaume. Le Douanier. In: APOLLINAIRE, Guillaume. Chroniques et paroles sur l'art. CEuvres en prose complètes. 3 vols. Textes établis, présentés et annotés par Pierre Caizergues et Michel Décaudin. Paris: Gallimard, 1991, vol. II, p. 627. Artigo publicado originalmente em Les Soirées de Paris, 15 de janeiro de 1914. Tradução minha.

4. Ibidem. 

amador. Nesse mesmo sentido, a paixão pela música diz muito sobre a natureza artística do Aduaneiro, já que se refletia igualmente na busca de uma expressão ora pictórica, ora literária. Não por acaso, no começo de sua carreira, foi identificado como "pintor de

5. UHDE, Wilhelm. Cinq Maîtres Primitifs. Rousseau - Vivin - Bombois - Bauchant - Séraphine. Traduction de l'allemand par Mlle. A. Ponchont. Préface d'Henri Bing-Bodmer. Paris: Philippe Daudy Éditeur, 1949, p. 33. 0 texto sobre Rousseau é retomado por Uhde, com modificações, de sua obra anterior: Henri Rousseau,

Paris: Figuière et Cie Éditeurs, 1911. Tradução minha.

6.TZARA, Tristan. Préface. In: LE PICHON, Yann (éd.). Les Écrits du Douanier Rousseau. Paris: CNRS Éditions, 2010, p. 77. Retomado da edição organizada por Tzara de Une Visite à l'Exposition de 1889, Genève: Pierre Cailler, 1947. Tradução minha.

7. Cf. MALINOWSKI, Holly. Les soirées musicales chez le Douanier Rousseau. In: BARBE, Michèle (dir.). Musique et arts plastiques. Analogies et interférences. Paris: PUPS, 2006, p. 133-142. Tradução minha.

8. APOLLINAIRE, Guillaume. Op. cit., p. 628. Tradução minha.

9. BRYARS, Gavin. Berners, Rousseau, Satie. In: NYMAN, Michael (ed.). Art \& Experimental Music. Studio International, vol. 192, n. 984, (special issue), 1976, November-December, p. 308-318. domingo”, aquele indivíduo que trabalha toda a semana e consagra os domingos a essa atividade favorita: a pintura. A atitude humanista do autodidata traduz, nesse contexto, uma concepção particular da arte, que é assumida como "uma entidade indivisível, os meios pelos quais toma forma não sendo senão acidentes fortuitos". ${ }^{6}$

De fato, Rousseau também era compositor, tendo escrito, nos anos 1880, uma valsa chamada Clémence, em homenagem à sua primeira esposa, Clémence Boitard, que lhe rendeu um diploma da Academia Literária e Musical de França. Mas, infelizmente, afora essa valsa "para violino ou mandolina", editada em 1904 por L. Barbarin, não sobreviveram outros exemplos da produção musical do artista. Não obstante, a partir dos programas preservados das soirées "literárias e musicais" que o Aduaneiro organizava em seu ateliê e nas quais tomavam parte alunos, vizinhos e amigos dos círculos artísticos como Marie Laurencin, Georges Duhamel, Max Jacob, Jules Romains, entre outros, pode-se recuperar alguns dos títulos de composições de sua lavra hoje perdidas: Les Deux Frères, Cécilette, Les Clochettes, Polka des bébés. Além disso, esses programas fornecem uma amostra do gosto musical do artista, formado por gêneros e estilos diversos, desde as melodias populares (mazurcas, polcas e valsas) até o repertório clássico (Bellini, Gounod, Franz Léhar). Enfim, uma fotografia do artista datada de 1906 [fig.1], dedicada por ele à filha, na qual aparece em seu ateliê cercado de quadros e empunhando o inseparável violino, revela-se verdadeira síntese das "analogias e interferências" envolvendo música e artes plásticas que se apresentam na sua própria obra e no cenário mais amplo de sua época ${ }^{7}$.

Essa característica levou Apollinaire a refletir que "a música nutria a pintura" ${ }^{8}$ de Rousseau. Mais adiante, ela também justificou sua presença, ao lado de Érik Satie e Berners, entre os chamados "pintores-músicos", conforme propôs Gavin Bryars. ${ }^{9}$ De fato, a música nutriu a pintura do artista em diversos momentos, e não 
apenas a pintura, pois suas peças de teatro estão recheadas de musicalidade. Em La Vengeance d'une orpheline russe, por exemplo, não há dificuldades em encontrar citações a compositores e obras, e o autor em diferentes momentos introduz ou a melodia do piano ou o toque da orquestra. Já em L'Étudiant en goguette, há toda uma atmosfera musical, sugerida pelo local onde se desdobra a trama, isto é, o cabaré do Chat Noir, e principalmente pela colagem de diversos trechos de canções (Le Bouquet de ménage, Les cambrioleurs, La Matschy) e ritmos dançantes populares à época (chahut, cancan, quadrilha). Em suma, a música definitivamente fazia parte da personalidade artística de Rousseau, que a desenvolvia, se não na mesma escala que a pintura, ao menos com o mesmo afinco. Inclusive, alguns aspectos identificados em sua linguagem plástica, como espontaneidade e primitivismo, foram considerados por François Sabatier ${ }^{10}$ valores essenciais nas correspondências entre música e arte no contexto de vanguarda. Esse aspecto estruturante é descrito também por Gilles Plazy ao considerar uma paisagem como O Jardim de Luxemburgo, Monumento a Chopin (1909), quando destaca, sobre a temática musical e a própria composição:

Que o músico Rousseau (ele tocava violino e compunha algumas pequenas obras) tenha escolhido esta vista do jardim sem dúvida não é um acaso. A homenagem a Frédéric Chopin é sem dúvida um argumento tão importante quanto a situação do monumento em um ângulo de aleia que permite ao pintor realizar uma dessas perspectivas curvas das quais tem o segredo [...]. Uma tal segurança plástica, no limite do desequilíbrio, importa mais do que a fidelidade às regras clássicas da representação. ${ }^{11}$

Mas, afinal, de que modo e por quais processos a música efetivamente alimentou a pintura de Rousseau? A observação atenta de sua obra pictórica, tomada em conjunto, leva a considerar que a influência da música, ou antes, a sua presença, dá-se em termos simbólicos, que vêm agregar um valor poético às composições, enriquecendo-as. Isso ocorre desde a mais remota produção do artista, pois sabe-se, pelo título de um dos primeiros quadros que expôs, Dança italiana (1885), obra hoje perdida, que a musicalidade já ali se insinuava. Além disso, o poema que acompanhava a pintura deixa adivinhar algo da atmosfera melódica que a composição certamente apresentava; nesse caso, permeada de bucolismo:
168

Andrei Fernando F. Lima

Iconografia musical na obra de Henri Rousseau

10. SABATIER, François.

Miroirs de la musique. La musique et ses correspondances avec la littérature et les beaux-arts 1800-1950. Paris: Fayard, 1995. Especialmente o capítulo “Du sauvage, de l'enfant et de l'aliéné. Candeurs naives du Douanier Rousseau à Érik Satie".

11. PLAZY, Gilles. Le Douanier Rousseau: Paysages. Coll. Le Musée Miniature. Paris: Éditions Herscher, 1994, p. 56. Tradução minha. 
12. "Par un beau dimanche de printemps,/Saison où la nature reprend sa splendeur,/ Voyez ces rustiques paysans,/ Inspirés d'une douce gaieté de cœur,/Danser sur le gazon verdoyant/Afin d'oublier de longs et rudes labeurs." RENOIR, Edmond. Exposition Libre des Beaux-Arts. Le XIXe

Siècle, Quinzième année, $\mathrm{n}^{0}$ 4873, 10 de maio de 1885, n. p. Tradução minha.

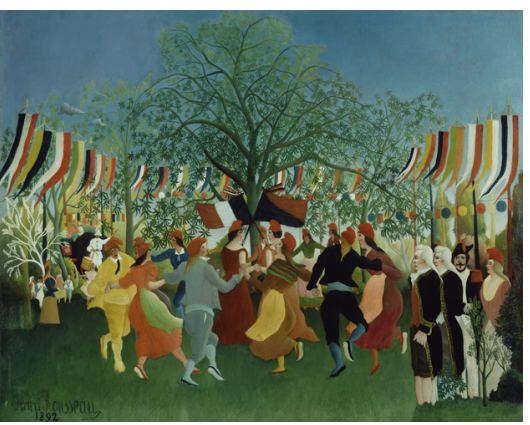

Figura 2: Henri Rousseau, Um Centenário da Independência, 1892. Óleo sobre tela, $111,8 x$ 157, $2 \mathrm{~cm}$, Los Angeles, The J. Paul Getty Museum.
Por um belo domingo de primavera,

Estação em que a natureza retoma seu esplendor,

Vede estes rústicos camponeses,

Inspirados por uma doce alegria de coração,

Dançarem sobre a grama verdejante

A fim de esquecer longos e rudes labores ${ }^{12}$.

No entanto, a música floresce na pintura de Rousseau mais frequentemente a partir de elementos sugestivos de sonoridade, compondo, nesse contexto, uma verdadeira iconografia musical. A mais antiga manifestação conhecida desse tipo de representação na sua obra surge de forma ostensiva em uma pintura alegórica de 1892 intitulada Um Centenário da Independência [fig.2], na qual o artista descreve patriotas dançando em roda das duas Repúblicas, de 1792 e de 1892, conforme indica a inscrição justaposta ao quadro. O desenho da cena foi inspirado em uma gravura de Fortuné Méaulle, Festas em Andorra (A farândola) (1891), e dela herda seu conteúdo musical, sendo a farândola uma dança provençal em que os participantes, homens e mulheres alternadamente, dão-se as mãos em formação circular. A pintura de Rousseau é dominada por um frondoso carvalho e contém, ainda, flâmulas e lampiões multicoloridos e personagens de catadura aristocrática que assistem imóveis à comemoração popular. Um importante elemento caracterizador da musicalidade observada nessa obra, porém, é a fanfarra que aparece ao fundo à esquerda. Do conjunto, formado por personagens de proporções reduzidas, destacam-se quatro instrumentos: um tambor, um trombone, uma caixa de percussão e um trompete. Sobre a carroça, personagens enchapelados tocam o tambor e o trombone; marchando à frente do veículo, um personagem com vestimenta branca toca a caixa de percussão, e uma menina de vestido rosa segura um trompete.

A ideia musical de Um Centenário da Independência apresenta-se através de uma articulação complexa que impõe nitidamente um ritmo à composição. Isso é alcançado pela cadência cromática das formas tanto quanto pelo sábio arranjo tonal entre as cores vibrantes dos trajes dos dançarinos em disposição circular e aquelas das bandeiras e lampiões em disposição semicircular. $\mathrm{O}$ 
contraponto, nesse sentido, é dado pela arvoreta arbitrariamente tingida de branco, à esquerda, que equilibra e harmoniza o conjunto. Por outro lado, o motivo da dança por si só implica as ideias de ritmo e musicalidade, valendo a lembrança de que George Bizet já elaborara uma melodia a partir do mesmo tema, a farândola, em sua ópera L'Arlésienne (1872). Mas o sentido da alegoria também deve ser levado em conta, uma vez que a proposta do artista foi conceber uma pintura de emulação da república (ele desejava que a tela fosse adquirida pelo Estado). A obra fala, por conseguinte, de patriotismo e união, dois princípios que o Aduaneiro ilustra em uma visão lúdica, musical e dançante, confirmada pela inscrição sob a moldura:

O povo dança em torno das duas Repúblicas, aquela de 1792 e aquela de 1892 dando-se as mãos ao som de: Auprès de ma blonde, qu'il fait bon, fait bon, fait bon etc ${ }^{13}$.

Mais do que uma simples legenda explicativa, esse texto é, na realidade, uma valiosa chave interpretativa da obra, pois explicita algo que não se pode transmitir pela linguagem pictórica: o som que o artista imaginou ao fazer dançar os personagens de sua composição. Em todo caso, o pintor italiano Ardengo Soffici, referindo-se a Um Centenário da Independência, mencionou "o horror cômico da turba jubilosa, dançando em uma praça, sem música, em torno de algum troféu republicano ou proletário, sob o olhar consentido das autoridades endomingadas e do 'guardião da paz' paternal". ${ }^{14}$ Na verdade, a música que simbolicamente ritmava os passos dos alegres dançarinos teria feito dançarem até mesmo os visitantes do Salão dos Independentes, onde a pintura foi apresentada, conforme o artista orgulhava-se de contar: "no dia do vernissage, todo mundo dançava diante do quadro, cantando: 'Auprès de ma blonde...” e "todo mundo estava feliz"15.

Outra aparição de um instrumento musical na pintura de Rousseau ocorreu cinco anos mais tarde, quando o artista criou a enigmática A Cigana adormecida (1897) [fig.3] . Tratase de um vasto quadro com o qual o Aduaneiro prestava tributo à tradição orientalista, dos grandes temas exóticos caros aos mestres acadêmicos que admirava, como Jean-Léon Gérôme e Félix-Auguste Clément. Em carta dirigida ao prefeito de sua cidade natal, a
170

Andrei Fernando F. Lima

Iconografia musical na obra de Henri Rousseau

13. "Le peuple danse autour des deux Républiques, celle de 1792 et celle de 1892 se donnant la main sur l'air de: Auprès de ma blonde, qu'il fait bon, fait bon, fait bon, etc." SALON DES INDÉPENDANTS.

Catalogue des CEuvres

Exposées. Société des Artistes Indépendants. 8me Exposition. Pavillon de la Ville de Paris (Champs-Elysées). Du 19 mars au 27 avril, 1892, p. 63. Tradução minha.

14. DUBOIS, Lucile (trad.). La France jugée à l'Étranger: Le peintre Henry [sic] Rousseau. In: VALLETTE, Alfred (dir.). Le Mercure de France, $n^{\circ} 320$, t. LXXXVII, 21e année, 16 de outubro de 1910, p. 751. Artigo publicado originalmente na revista italiana La Voce, $\mathrm{n}^{0}$ 40, 15 de setembro de 1910. Tradução minha.

15. ALEXANDRE, Arsène. La vie et l'œuvre d'Henri Rousseau: peintre et ancien employé de l'octroi. Comoedia, 4e année, no 901 (Quotidien), 19 de março de 1910, p. 3. Tradução minha. 
16. Carta datada de 10 julho de 1898. 0 fac-símile do documento encontra-se reproduzido em: VALLIER, Dora. Henri Rousseau. Paris: Flammarion, 1961, fig. 1-2. Transcrição e tradução de minha autoria.

17. Ibidem, p. 66 .
Uma negra errante, tocando mandolina, tendo seu jarro ao lado dela (vaso contendo água para beber), dorme profundamente exausta de fadiga. Um leão passa por acaso, a fareja, e não a devora. É um efeito de lua, muito poético. A cena se passa num deserto completamente árido. A cigana está vestida à oriental ${ }^{16}$.

Juntos, a mandolina e o jarro compõem um belo trecho de natureza-morta, cuja memória plástica não terá deixado de influenciar artistas como Matisse, Picasso e Braque. No entanto, o que interessa aqui é a simbologia desse instrumento, certamente descrito a partir de uma mandolina napolitana pertencente ao próprio artista, que também nela era versado (vide a valsa Clémence). $\mathrm{O}$ instrumento remete às origens mesmas do personagem, como na obra de Camille Corot, Cigana com mandolina (1874), é um atributo seu, enfatizando uma narrativa que, segundo anota Dora Vallier, "se insinua, quem sabe, longe nessas histórias de boêmios, ciganos e gitanos, em voga nessa época, roça talvez alguma lembrança de quermesse, de zíngaros com suas feras [...]”, em suma, completa a autora,

todos os lugares-comuns concernindo essa raça de gente estão inscritos no quadro um a um. Nômades - ver o jarro e o bastão; bizarramente vestidos - ver a estranha vestimenta estriada; tocando música frequentemente para ganhar a vida - ver a mandolina; feiticeiros à ocasião - ver o leão que fareja a cigana e não a devora ${ }^{17}$.

A mandolina sem dúvida empresta à proposta semântica da pintura um valor considerável, sugere efetivamente uma melodia misteriosa, exótica, própria ao universo narrativo explorado pelo artista e assim acentua o "efeito poético" que se buscava alcançar nessa composição heterogênea, na qual cada elemento surge investido de profundo lirismo. Em outros termos, a música, aqui representada pelo instrumento, conta toda uma história, traduz as intenções do pintor ao tecer a cena, além de seduzir o espectador em sua imaterialidade e imanência. 
18. ALEXANDRE, Arsène. op. cit.

Figura 5: Henri Rousseau,

A Liberdade convidando os artistas a participarem da $22^{a}$ exposição da Sociedade dos Artistas Independentes, 1906. Óleo sobre tela, $175 \times 118$ $\mathrm{cm}$. Museu de Arte Moderna, Tóquio.
Bartholdi, O Leão de Belfort, guardião de Paris, e mantém sob as patas um pergaminho em que se lê: "Os Valton, Signac, Carrière, Willette, Luce, Seurat, Ortiz, Pissaro, Jaudin, Henri Rousseau etc. etc. são teus êmulos”. Acima das flâmulas com as cores da França e de Paris, das bandeiras internacionais e das árvores frondosas, paira o elemento dominante da composição: uma figura feminina alada, vestida com uma túnica rosa e tocando um clarim. Trata-se da imagem alegórica da Liberdade, que o Aduaneiro concebeu a partir de uma ampla iconografia, de um vasto repertório de figuras aladas anunciadoras, de matriz bíblica ou mitológica, soprando trombetas ou clarins. Da qual se deduz o sentido desse tipo de construção, pelo qual o artista pretendia louvar o espírito democrático do salão, o primeiro a excluir júris e prêmios, de modo a exaltar aquela que ele considerava como "a mais bela Sociedade, a Sociedade mais legal, posto que todo mundo tem o mesmo direito" ${ }^{18}$.

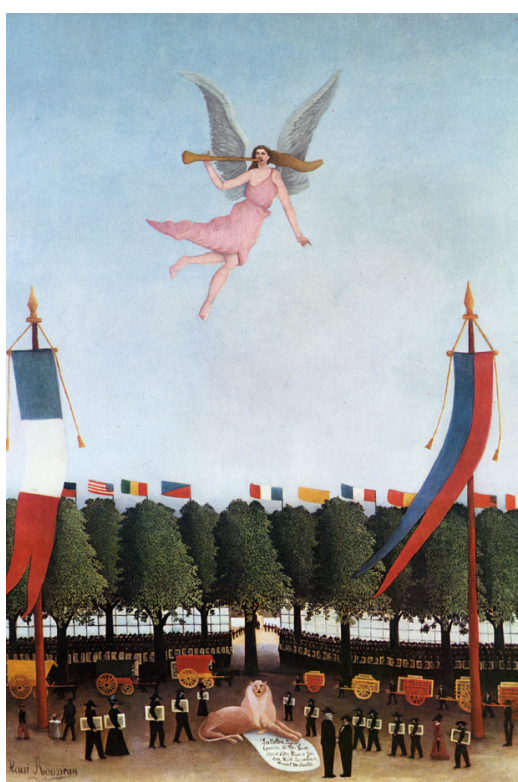

Outra vez ainda, a flauta torna a surgir na pintura $A$ Encantadora de serpentes [fig.6], obra de grandes dimensões criada em 1907 por encomenda da mãe do pintor Robert Delaunay, um dos amigos próximos de Rousseau. O tema exótico e a atmosfera 
sobrenatural dessa pintura foram pensados pelo artista a partir dos relatos que ouvira de Madame Delaunay sobre a viagem que fizera à Índia e histórias a respeito de encantadores de serpentes. Em sua complexa narrativa visual, o Aduaneiro explorou a ideia dos poderes mágicos e encantatórios atribuídos à melodia de certos instrumentos, em particular da flauta, um dos mais antigos de que se tem conhecimento. Nesse contexto, é impossível não recordar as fábulas populares, como a do flautista de Hamelin, ou o mito de Orfeu, de longa fortuna nas artes e nas letras, pela maneira como a encantadora atrai, com as notas derramadas da flauta, não apenas serpentes, mas também pássaros e uma grande ave pescadora. Ao amante da música Rousseau, ademais, certamente não era desconhecida uma passagem do primeiro ato de A Flauta Mágica (1791), aquela do embevecimento das feras pelo príncipe Tamino, quando esse personagem declama os famosos versos: "Que poderoso é seu som mágico,/linda flauta, pois quando lhe escutam,/ até as feras selvagens se apaziguam [...]"19, cuja simbologia é aqui refletida. Tudo na cena remete ao plano onírico e ao mistério, evocando imagens e memórias que afloram somente nos sonhos e no inconsciente. Trata-se, por isso mesmo, de um momento supremo da presença musical na pintura de Rousseau, justamente pelas inflexões que atinge. A música representada, nesse sentido, é capaz de inspirar sinestesicamente a música real: Eric Montbel, tocador de cornamusa, instrumento próximo à sonoridade da flauta descrita, compôs, a partir da sugestão pictórica, A Encantadora de serpentes (2004), espetáculo musical sobre a obra do Aduaneiro.

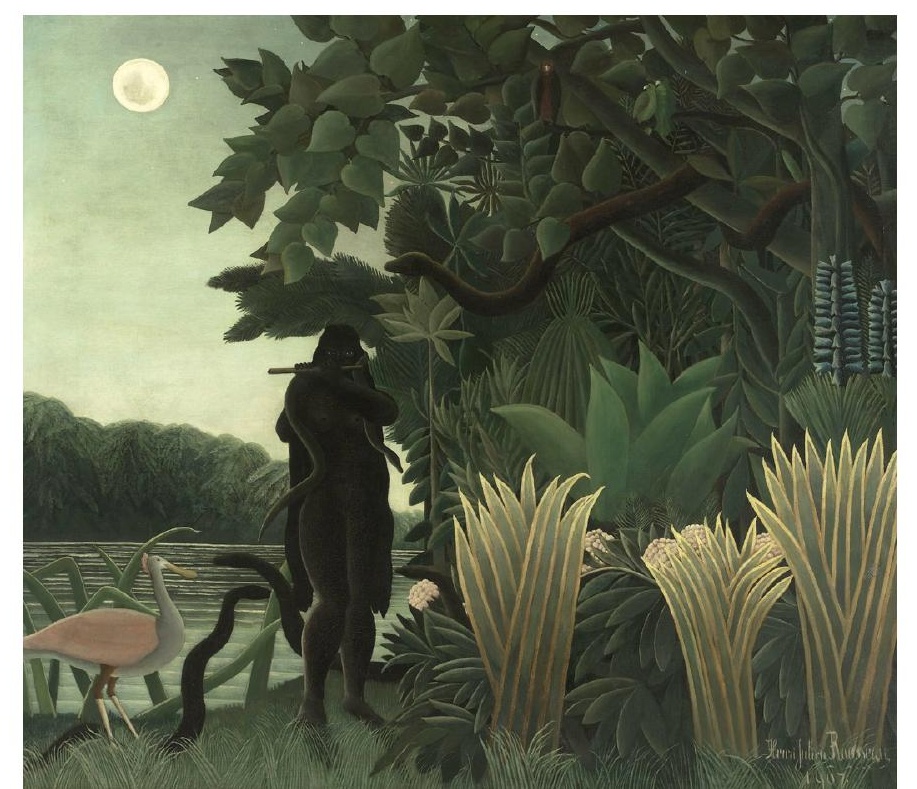

174

Andrei Fernando F. Lima

Iconografia musical na obra de Henri Rousseau

19. "Wie stark ist nicht dein Zauberton,/Weil, holde Flöte, durch dein Spielen/Selbst wilde Tiere Freude fühlen [...]". MOZART, Wolfgang Amadeus.

A Flauta Mágica. Libreto de Emanuel Schikaneder. Trad. Mariana Portas. Col. Folha Grandes Óperas. Vol. 5. $2^{\mathrm{a}}$ ed. São Paulo: Moderna, 2011, p. 39.

Fig. 6

Henri Rousseau, A Encantadora de serpentes, 1907. Óleo sobre tela, $169 \times 189 \mathrm{~cm}$. Museu d'Orsay, Paris. 

de Rousseau, por se tratar de uma obra-síntese no contexto de

20. APOLLINAIRE, Guillaume; CERUSSE, Jean (dir.). Les Soirées de Paris, $n^{\circ} 20,15$ de janeiro de 1914, p. 56.

21. APOLLINAIRE, Guillaume. Prenez garde à la peinture! Le Salon des Artistes Indépendants six mille toiles sont exposées [Le mysticisme de Grieud. Le charme de Marie

Laurencin. Un nu solide de Jean Metzinger. La Vulgarité de Van Dongen]. In: APOLLINAIRE, Guillaume. Chroniques et paroles sur l'art. CEuvres en prose complètes. 3 vols. Textes établis, présentés et annotés par Pierre Caizergues et Michel Décaudin. Paris: Gallimard, 1991, vol. II, p. 144.

22.ALEXANDRE, Arsène. Op. sua criação, a música surge pela derradeira vez e com máxima expressividade. Trata-se de O Sonho [fig.7], última tela do artista apresentada no Salão dos Independentes, em 1910, pouco antes da sua morte, que ocorreu no mês de setembro. Em carta endereçada a Apollinaire e datada de 11 de março, o Aduaneiro dava-lhe a notícia da conclusão da obra e lhe fazia um pedido: "Enviei meu grande quadro, todo mundo o acha bom, penso que tu vais ostentar teu talento literário e me vingarás de todos os insultos e afrontas recebidos”. ${ }^{20}$ A resposta do poeta veio rápida e precisa em sua resenha de arte do jornal L'Intrinsigeant, no dia 18 de março:

[...] sobre um sofá 1830, dorme uma mulher nua. Em torno cresce uma vegetação tropical onde vivem macacos e aves-do-paraíso e, enquanto um leão e uma leoa passam tranquilamente, um negro - personagem de mistério - toca o galubé. Desse quadro emana a beleza, é incontestável... Acredito que, neste ano, ninguém ousará rir... Perguntem aos pintores. Todos são unânimes: eles admiram. Eles admiram tudo, eu digo, mesmo este canapé Luís-Filipe perdido na floresta virgem, e eles têm toda razão ${ }^{21}$.

O comentário é também uma eficiente descrição da cena pintada por Rousseau, o encontro enigmático de uma mulher nua reclinada sobre um canapé vermelho com animais selvagens (leões, macacos, serpentes e pássaros) e com um músico negro em plena floresta tropical. Antevendo talvez a dificuldade que os espectadores encontrariam ao tentar decifrar a imagem e sabendo, como dizia, que "nem sempre as pessoas compreendem aquilo que veem" ${ }^{22}$, Rousseau escreveu um poema explicativo para o quadro, concebido nos seguintes termos:

Yadwigha num belo sonho

Estando adormecida docemente

Escutava os sons de uma cornamusa

Que tocava um encantador benévolo.

Enquanto que a lua reflete

Sobre as flores, as árvores verdejantes, 
As fulvas serpentes prestam ouvidos

Às melodias alegres do instrumento ${ }^{23}$.

Ao identificar a figura feminina com o nome próprio Yadwigha, o artista pensava esclarecer algo acerca do conteúdo da pintura aos olhos do público, porém dificilmente alguém seria capaz de fazêlo, desconhecendo as origens desse nome e suas implicações na narrativa visual de $O$ Sonho. Isso porque Yadwigha, nome repetido por Rousseau em diferentes ocasiões e que se referia a uma jovem polonesa que fora seu amor de juventude, também nomeia um personagem do drama La Vengeance d'une orpheline russe, precisamente a tia da protagonista. Ora, essa correlação define um intertexto impossível de ser detectado pelos contemporâneos do Aduaneiro, já que sua peça não chegou a ser publicada senão tardiamente. Mas, quando se tem a acesso à peça, ao poema e ao quadro, tudo faz sentido, uma vez que, no segundo ato desse drama, encontramos esta curiosa fala de Yadwigha:

Meu Deus! que dia quente; eu acreditaria estar no Senegal ou num desses países exóticos onde florestas imensas de árvores de um colorido esplêndido são habitadas por antropófagos ou feras mais ou menos terríveis ${ }^{24}$.

A relação aqui tecida, logo se constata, é de ordem conceitual, e ocorre a partir da retomada da metáfora empregada pelo personagem. A pintura, então, vista a partir da leitura do poema, apresenta-se como uma espécie de transcrição iconográfica dessa metáfora, como um correlato plástico da imagem literária. Assim, portanto, justifica-se a presença insólita do canapé naquele contexto: trata-se de uma lembrança do mundo real que determina, por contraste, a irrealidade da paisagem ao redor - aquilo que, em pintura, nomeia-se "paisagem mental" (a representação de uma projeção do inconsciente do personagem). E, como se não bastasse, Rousseau deixou por escrito um valioso esclarecimento. Em carta ao crítico André Dupont, datada de $1^{\circ}$ de abril de 1910, explicava a ficção servindo de suporte à cena: "A mulher adormecida sobre o canapé sonha que ela foi transportada para essa floresta, ouvindo os sons do instrumento do encantador. Isso dá o motivo pelo qual o canapé está no quadro"25.
23. "Yadwigha dans un beau rêve/S'étant endormie doucement/Entendait les sons d'une musette/Dont jouait un charmeur bien pensant./ Pendant que la lune reflète/ Sur les fleurs, les arbres verdoyants,/Les fauves serpents prêtent l'oreille/Aux airs gais de l'instrument." Ibidem.

24. ROUSSEAU, Henri. La Vengeance d'une orpheline russe. In: LE PICHON, Yann (éd.). Les écrits du Douanier Rousseau. Présentés par Yann le Pichon. Paris: CNRS Éditions, 2010, p. 162.

25. APOLLINAIRE, Guillaume; CERUSSE, Jean (dir.). Les Soirées de Paris, $n^{\circ} 20,15$ de janeiro de 1914, p. 57. 
Figura 7: Henri Rousseau, O Sonho, 1910. Óleo sobre tela, $204,5 \times 298,5 \mathrm{~cm}$. The Museum of Modern Art, Nova York.

26. ALEXANDRE, Arsène. Henri Rousseau, peintre et douanier. Le Figaro. $56 \mathrm{e}$ Année, 3e Série, nº 248, 1910.

p. 1.

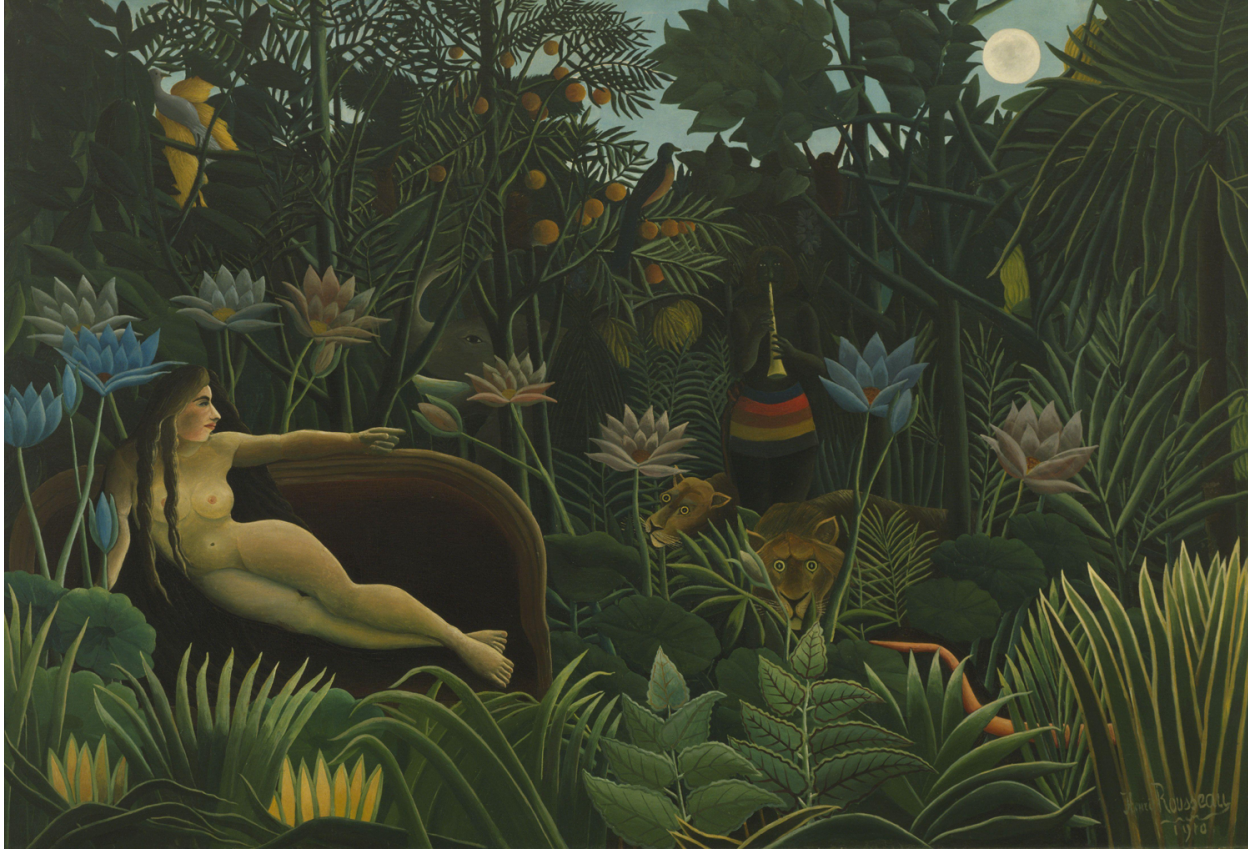

O sentido da narrativa subjacente contextualiza a presença da música nessa pintura. Para tanto, é necessário examinar mais detidamente esse "personagem de mistério", referido pelo artista em seu poemeto como "encantador benévolo", responsável que é pela hipnose da mulher e dos animais à sua volta. Em primeiro lugar, deve-se esclarecer que o instrumento que aparece representado em suas mãos não é um galubé, tal como dito por Apollinaire, nem tampouco uma flauta, como mencionam outros autores, mas, de acordo com Rousseau, uma musette, ou cornamusa, instrumento folclórico da família da gaita de foles, de sons agudos, que, na mesma época, era introduzido na orquestração moderna por Déodat de Séverac ${ }^{26}$. A escolha dessa designação tão precisa, e ao mesmo tempo tão desconcertante em seu significado, escapa totalmente à percepção, muito embora deva subordinar-se ao exotismo que o pintor explora no quadro, ajustando-se, por conseguinte, à própria semântica da obra. Reaparece, nesse caso, a figura do encantador, que, através dos sons que extrai de seu instrumento, seduz pessoas e animais, e reaparece igualmente o tema do poder encantatório da música, já buscado em A Encantadora de serpentes. São efetivamente as "alegres melodias" da cornamusa que transportam Yadwigha para a floresta virgem, imergindo-a em um sonho doce em que até mesmo os leões e serpentes "prestam ouvidos” ao instrumento. Não é surpresa, então, reencontrar, como reminiscência lírica, o mesmo personagem e melodia em "Hommage à Érik Satie", poema escrito por Jean Cocteau, em 1918, e musicado por Georges Auric: 
A lua entra na flauta

Do encantador negro

Yadwigha adormecida escuta

E sai da doce flauta

Um trecho em forma de pera ${ }^{27}$.

A presença de instrumentos, transmitindo metonimicamente o efeito de musicalidade em todas essas pinturas, pode ser interpretada de modos variados. O exercício musical praticado por Rousseau é uma primeira possibilidade acerca da compreensão desse fenômeno, já que define uma convergência poética concreta entre a linguagem da música e a linguagem da pintura em sua produção. Seriam os flautistas que surgem em Quarteto feliz e em O Sonho, nesse sentido, projeções do próprio artista realizando outra performance, ação espelhada agora na tela? Para Ann Temkin, de fato "a música imaginária do músico pintado é uma metáfora para o poder de encantamento da própria pintura” ${ }^{28}$. Por outro lado, essa presença também pode ser assumida em um contexto mais amplo, precisamente aquele da arte simbolista dos anos finais do século XIX e do início do século XX, que valorizava a melodia e o poder de sugestão da música como importantes constructos. O papel desempenhado pela música em A Cigana adormecida e, particularmente, em A Encantadora de serpentes é revelador de uma atmosfera de encantamento, de mistério e de fantasia típica do Simbolismo, que muito se aproxima do trabalho de Paul Gauguin, outro artista fascinado pelos efeitos singulares do som na construção de imagens contemplativas e atemporais, como é o caso das cenas taitianas. Nesses quadros, a música, enfim, como metáfora de encantamento, introduziria uma dimensão mística, a qual também não era ignorada pelos simbolistas, nem mais adiante pelos surrealistas, por recorrentes associações à hipnose e ao transe, temas que o Aduaneiro demonstra conhecer ou pelo menos intuir sensivelmente $\mathrm{e}^{29}$.

De modo geral, semelhantes correlações entre linguagens na obra de Rousseau sugerem um modo complexo de orquestração de ritmos e melodias, não apenas pela invocação de uma determinada sonoridade vinculada a um instrumento específico, como a
Iconografia musical na obra de

Henri Rousseau

27. "La lune entre dans la flûte/Du charmeur noir/ Yadwigha endormie écoute/ Et il sort de la douce flûte/Un morceau en forme de poire". LE PICHON, Yann. Théâtre complet. In: LE PICHON, Yann. (éd.). Les Écrits du Douanier Rousseau. Paris: CNRS Éditions, 2010, p. 74.

28. TEMKIN, Ann. Rousseau. The Dream. Coll. 1 On One. New York: The Museum of Modern Art, 2012, p. 39.

29. Em ensaio dedicado ao tema, Pascal Rousseau desdobra a voga do hipnotismo na Belle Époque e sua abordagem científica, demonstrando suas relações com o florescimento dessa 
iconografia na obra do Aduaneiro. Nesse caso, o pesquisador destaca a obra clássica de Foveau de Courmelles, publicada em 1890, Hypnotisme et croyances anciennes, na qual o autor dedica um capítulo ao sono provocado nos animais, com um longo desenvolvimento

sobre os Aissouas, ou encantadores de serpentes do Marrocos, presentes na Exposição Universal de Paris de 1889. Na obra do artista autodidata, as ideias de encantamento pela música e das transformações que ela é capaz de induzir são extraídas diretamente desse universo. Cf. ROUSSEAU,

Pascal. La magie des images. Hallucination et rêverie magnétique dans l'œuvre d'Henri Rousseau. In: Le Douanier Rousseau. Jungles à Paris. Trad. de l'anglais par Hélène Tronc. Catálogo de exposição, Galeries nationales du Grand Palais, Paris, 15 mar. - 19 jun. 2006. Paris: Réunion des Musées Nationaux, 2006,

p. 201. musicalidade. Por ter sido músico, o artista conhecia profundamente o apelo exercido por uma melodia e é com base nessa percepção que representa a música em seus quadros, conseguindo transmitir toda a força e o poder evocativo da mais abstrata e inefável das linguagens artísticas. A música aparece em sua produção como sugestão de uma sensação, como argumento para uma narrativa, como expressão de um tema, de forma a reiterar ideias que serão identificadas a ritmos, timbres, melodias e efeitos de sentido que vão da solenidade à comemoração festiva, do encantamento ao feitiço, aos quais os espectadores, por certo, são sensíveis. Suas pinturas concretizam, por conseguinte, o esforço superior da correspondência entre as artes, que, por sinal, terá sido uma das marcas mais significativas da modernidade.

\section{Bibliografia}

ALEXANDRE, Arsène. La vie et l'œuvre d'Henri Rousseau: peintre et ancien employé de l'octroi. Comoedia, $4 \mathrm{e}$ année, $\mathrm{n}^{\circ} 901$ (Quotidien), 19 de março de 1910.

ALEXANDRE, Arsène. Henri Rousseau, peintre et douanier. Le Figaro. 56e Année, 3e Série, no 248, 1910.

APOLLINAIRE, Guillaume; CERUSSE, Jean (dir.). Les Soirées de Paris, $n^{\circ} 20,15$ de janeiro de 1914.

APOLLINAIRE, Guillaume. Chroniques et paroles sur l'art. Euvres en prose complètes. 3 vols. Textes établis, présentés et annotés par Pierre Caizergues et Michel Décaudin. Paris: Gallimard, 1991. 
APOLLINAIRE, Guillaume. Prenez garde à la peinture! Le Salon des Artistes Indépendants six mille toiles sont exposées [Le mysticisme de Grieud. Le charme de Marie Laurencin. Un nu solide de Jean Metzinger. La Vulgarité de Van Dongen]. In: Chroniques et paroles sur l'art. Euvres en prose complètes. 3 vols. Textes établis, présentés et annotés par Pierre Caizergues et Michel Décaudin. Paris: Gallimard, 1991, vol. II.

LE PICHON, Yann (éd.). Les Écrits du Douanier Rousseau. Paris: CNRS Éditions, 2010.

MALINOWSKI, Holly. Les soirées musicales chez le Douanier Rousseau. In: BARBE, Michèle (dir.). Musique et arts plastiques. Analogies et interférences. Paris: PUPS, 2006, p. 133-142.

MOZART, Wolfgang Amadeus. A Flauta Mágica. Libreto de Emanuel Schikaneder. Trad. Mariana Portas. Col. Folha Grandes Óperas. Vol. 5. $2^{\text {a }}$ ed. São Paulo: Moderna, 2011.

NYMAN, Michael (ed.). Art \& Experimental Music. Studio International, vol. 192, n. 984, (special issue), 1976, NovemberDecember, p. 308-318.

PAYRÓ, Julio E. El Aduanero Rousseau. Biblioteca Argentina de Arte. Buenos Aires: Editorial Poseidon, 1944.

PLAZY, Gilles. Le Douanier Rousseau: Paysages. Coll. Le Musée Miniature. Paris: Éditions Herscher, 1994.

RENOIR, Edmond. Exposition Libre des Beaux-Arts. Le XIXe Siècle, Quinzième année, ${ }^{\circ}$ 4873, 10 de maio de 1885 .

ROUSSEAU, Pascal. La magie des images. Hallucination et rêverie magnétique dans l'œuvre d'Henri Rousseau. In: Le Douanier Rousseau. Jungles à Paris. Trad. de l'anglais par Hélène Tronc. Catálogo de exposição, Galeries nationales du Grand Palais, Paris, 15 mar. - 19 jun. 2006. Paris: Réunion des Musées Nationaux, 2006, p. 193-205. 
Paris: Fayard, 1995.

\section{SALON DES INDÉPENDANTS. Catalogue des Cuvres Exposées.}

Société des Artistes Indépendants. 8me Exposition. Pavillon de la Ville de Paris (Champs-Elysées). Du 19 mars au 27 avril, 1892.

SOFFICI, Ardengo apud DUBOIS, Lucile (trad.). La France jugée à l'Étranger: Le peintre Henry [sic] Rousseau. In: VALLETTE, Alfred (dir.). Le Mercure de France, $n^{\circ}$ 320, t. LXXXVII, 21 e année, 16 de outubro de 1910.

TEMKIN, Ann. Rousseau. The Dream. Coll. 1 On One. New York: The Museum of Modern Art, 2012.

UHDE, Wilhelm. Cinq Maîtres Primitifs. Rousseau - Vivin Bombois - Bauchant - Séraphine. Traduction de l'allemand par Mlle. A. Ponchont. Préface d'Henri Bing-Bodmer. Paris: Philippe Daudy Éditeur, 1949.

VALLIER, Dora. Henri Rousseau. Paris: Flammarion, 1961.

Andrei Fernando Ferreira Lima é Bacharel em Letras (2014) e Mestre (2016) pela Universidade de São Paulo, onde atualmente desenvolve pesquisa de doutoramento pelo Programa de PósGraduação em Estudos Linguísticos, Literários e Tradutológicos em Francês. Atua nas áreas de Literatura Francesa, Literatura Comparada e Teoria da Arte. 